\title{
PENINGKATAN PERAN SERTA MASYARAKAT DALAM PEMANFAATAN LAHAN PEKARANGAN MELALUI PENANAMAN POHON EKONOMIS DI DESA CIHERANG, BOGOR, JAWA BARAT
}

\section{(The Improving Roles and Communities on The Yard Area Utilization Through Tree Planting in Ciherang Village, Bogor, West Java)}

\author{
DAFIT ARIYANTO', SAIJO ${ }^{2}$ \\ 1. Program Studi Budidaya Perairan, Fakultas Pertanian, Universitas Asahan, JI Ahmad \\ Yani, Kisaran, 21224, Sumatera Utara
}

2. Program Studi Agroteknologi, Fakultas Pertanian dan Kehutanan, Universitas, JI RTA. Milono km 1.5, Muhamadiyah Palangkarya,73111, Kalimatam Tengah

Email: dafitariyanto676@gmail.com

\begin{abstract}
The yard is a green open space that has economic value. The society's devotion was conducted on Sunday, October 22, 2017 in Ciherang Village, Bogor, West Java. The purpose of community service was to grow the spirit of public awareness of the importance of preserving the environment within the scope of the family and the surrounding environment. The method used was FGD (Foccus Discussion Group) method and application. The research used descriptive analysis. The results showed that the high enthusiasm and awareness about environmental awareness in the field of yard. Overall awareness raising of the community requires cooperation between various parties.
\end{abstract}

Key words: Focus Group Discussion, yard area, community, patnership

\begin{abstract}
Abstrak
Pekarangan merupakan ruang terbuka hijau yang memiliki nilai ekonomi.Pengabdian masyarakat ini dilaksanakan pada Minggu, 22 Oktober 2017 di Desa Ciherang Bogor, Jawa barat. Tujuan pengabdian masyarakat ini untuk menumbuhkan jiwa kesadaran masyarakat pentingnya menjaga kelestarian lingkungan dalam ruang lingkup keluarga dan lingkungan sekitar. Metode yang digunakan adalah metode FGD (Foccus Discussion Group) dan aplikasi. Analisis penelitian ini menggunakan analisis deskripsi. Hasil pengabdian masyarakat ini menghasilkan antusias dan kesadaran yang tinggi mengenai kesadaran lingkungan dalam lingkup pekarangan. Secara keseluruhan peningkatan kesadaran masyarakat diperlukan kerjasama antara berbagai pihak.

Kata Kunci : Fokus Group Diskusi, pekarangan, masyarakat, kerjasama.

\section{PENDAHULUAN}

Jumlah penduduk yang tinggi tidak pernah lepas dari kebutuhan perumahan di kota. Menurut BPS (2013) bahwa penggunaan lahan meningkat dengan peningakatan perumahan. Tingkat kepadatan rumah dalam suatu

permukiman diikuti dengan keterbatasan ruang sekitar rumah yang dimanfaatkan dan diberdayakan untuk pekarangan. Pekarangan merupakan ruang terbuka hijau yang dapat mendukung gerakan lingkungan kota cerdas. Menurut Departemen Kehutanan (2005),
\end{abstract}


pekarangan dapat memberikan prestise tertentu. Oleh sebab itu pekarangan dapat ditata sedemikian rupa untuk mendapatkan citra, kebanggaan dan keindahan tertentu.

Penghijauan merupakan kegiatan penting yang harus dilaksanakan secara konseptual dalam menangani krisis lingkungan. Penghijauan sangat dibutuhkan terutama untuk kota-kota yang sedang berkembang dan mengalami alih fungsi ruang untuk kawasan terbangun (Kelvin 2008). Begitu pentingnya sehingga penghijauan sudah merupakan program nasional yang dilaksanakan di seturuh Indonesia. Penghijauan dapat digunakan sebagai pengatur tata air atau pelindung lingkungan.

Manusia merupakan bagian dari komponen lingkungan hidup yang senantiasa saling mempengaruhi. Pengaruh manusia terhadap lingkungannya sangatlah besar. Dengan pengetahuan dan teknologi, manusia mampu mempertahankan diri atau menyesuaikan diri dengan lingkungannya. Berdasarkan Undang-Undang Nomor 23 Tahun 1997 tentang Pengelolaan Lingkungan Hidup disebutkan bahwa lingkungan hidup adalah kesatuan ruang dengan semua benda, daya, keadaan, dan makhluk hidup, termasuk manusia dan perilakunya, yang memengaruhi kelangsungan peri kehidupan dan kesejahteraan manusia serta makhluk hidup lain.

Penghijauan dapat dilakukan
dengan aktivitas menanam pohon.
Penghijauan merupakan kegiatan salah satu cara melestarikan alam, mengingat bahwa pohon mempunyai banyak sekali manfaat, tidak hanya bagi lingkungan atau alam, namun juga bagi makhluk hidup baik manusia maupun binatang. Penghijauan sangat dibutuhkan untuk menciptakan lingkungan yang sejuk, segar, nyaman dan sehat. Pohon yang ditanam dalam aktivitas penghijauan boleh bermacam- macam jenis pohon. Biasanya pohon yang ditanam adalah pohon- pohon yang mempunyai berbagai fungsi yaitu pohon buah buahan. Irwan et al. (2015) melaporkan bahwa jenis-jenis tanaman yang ditanam di pekarangan, di antaranya pohon buah seperti nangka, mangga, asem), tanaman rempah dan obat (jahe, laos, sirih), sayuran (sawi, cabe, bayam) dan tanaman hias (aglonema, anthurium, mawar). Tujuan penelitian ini untuk menentukan peran masyarakat dalam kegiatan penghijauan.

\section{MATERI DAN METODE}

\section{Waktu dan Tempat}

Pengabdian masyarakat dilaksanakan pada Minggu, 22 Oktober 2017 dengan waktu pelaksanaannya pada pukul 07.00 - selesai dan di Desa Ciherang Bogor, Jawa barat.

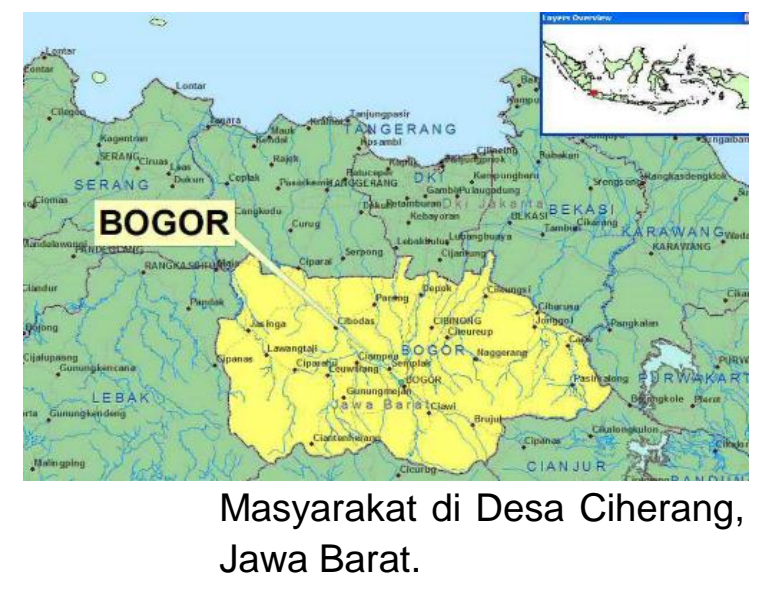

\section{Bahan dan Metode Penelitian}

\section{Desain Penelitian}

Tahap Persiapan. Tahap ini meliputi kegiatan perizinan baik menyangkut lokasi, waktu, dan tempat pelaksanaan penelitian. Tahap persiapan ini juga menyangkut persiapan bahan yaitu bibit pohon, cangkul, pupuk, air, dan nametage (pohon dan penanam). Responden dalam penelitian ini meliputi tokoh masyarakat, 
takmir masjid, ketua karang taruna dan relawan.

\section{Tahap Pelaksanaan}

Tahap ini meliputi kegiatan sambutan oleh kepala desa, tokoh masyarakat, penyampaian atau presentasi materi pentingnya pemanfaatan pohon bagi keluarga dan lingkungan. Kegiatan terakhir penelitian ini dengan pembagian bibit ke masyarakat dan penanaman simbolis oleh kepala desa, tokoh masyarakat, dan relawan.

\section{Metode penelitian}

Metode penelitian ini menggunakan metode FGD (Foccus Discussion Group). Metode ini mengandalkan perolehan data atau informasi dari suatu interaksi informan atau responden berdasarkan hasil diskusi dalam suatu kelompok yang berfokus untuk melakukan bahasan dalam menyelesaikan permasalahan tertentu (Afiyanti 2008). Kitzinger dan Barbour (1999) adalah melakukan eksplorasi suatu isu/fenomena khusus dari diskusi suatu kelompok individu yang berfokus pada aktivitas bersama diantara para individu yang terlibat didalamnya untuk mengh asilkan suatu kesepakatan bersama.

\section{Analisis Data}

Analisis statistik deskriptif adalah statistik yang digunakan untuk menganalisis data dengan cara mendeskripsikan atau menggambarkan data yang telah terkumpul sebagaimana adanya tanpa melalui gambar dan persepsi masyarakat.

\section{HASIL DAN PEMBAHASAN}

\section{Hasil}

Pengabdian masyarakat ini di ikuti oleh mahasisswa pascasarjana IPB dan masyarakat Desa Ciherang, dan serta tokoh masyarakat Desa Ciherang, Bogor,
Jawa Barat. Gambar 2 menggambarkan bahwa masyarakat dalam forum diskusi sangat antusias dalam partisipasi mengembangkan Pekarangan Produktif. Masyarakat memiliki harapan dapat menanam lebih banyak tanaman buah, sayuran, hias, rempah, dan obat/herbal, dimana jenis ini termasuk kategori tanaman hortukultura. Partisipasi masyarakat sering diartikan keikutsertaan, keterlibatan dan kesamaan anggota masyarakat dalam suatu kegiatan tertentu baik secara langsung maupun tidak langsung, sejak dari gagasan, perumusan kebijakan, pelaksanaan program dan evaluasi.

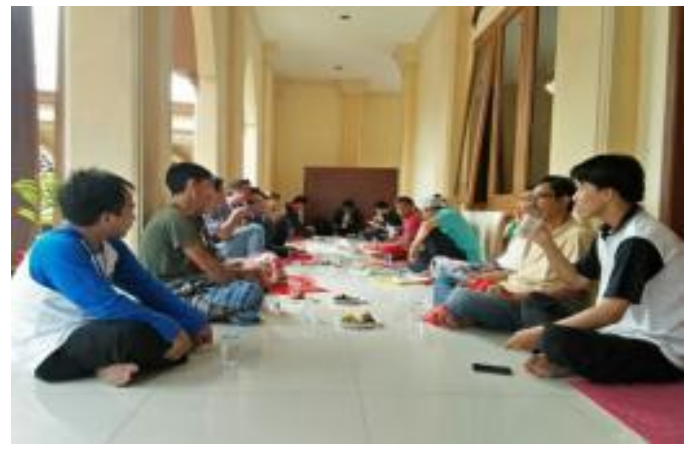

Gambar 2. Foccus Discussion Group dengan masyarakat di Desa Ciherang Bogor Jawa Barat

Partisipasi secara langsung berarti anggota masyarakat tersebut ikut memberikan bantuan tenaga dalam kegiatan yang dilaksanakan. Akhir kegitan ini dilakukan pembagian bibit buah kepada masyarakat Desa Ciherang sebanyak 1000 bibit buah. Selain itu, adanya kegiatan penanaman simbolis oleh masyakat (Gambar 3). Kegiatan melestarikan lingkungan dapat dimulai dengan mencintai lingkungan di sekitar kita yaitu pada tetumbuhan dan pepohonan di pekarangan rumah. Pekarangan rumah walaupun sempit dapat dimanfaatkan untuk menanam tumbuhan yang bermanfaat. Memulai dari rumah sendiri dengan satu dua pohon dapat menuju cakupan yang lebih luas. Pemanfaatan pekarangan dapat 
digunakan untuk meningkatkan pemenuhan gizi mikro melalui perbaikan menu keluarga, menumbuhkan kesadaran keluarga agar mengenali dan mengetahui sumber-sumber pangan yang ada disekitar kita, menumbuhkan kesadaran keluarga agar mau dan mampu memanfaatkan lahan pekarangan menjadi sumber pangan dan gizi keluarga.

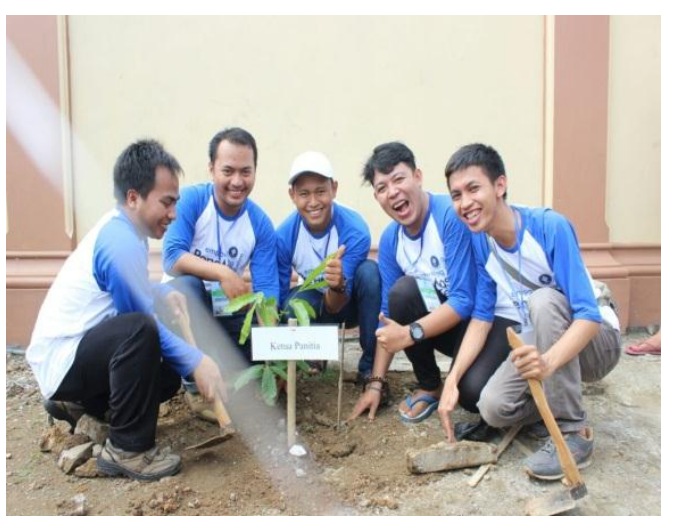

Gambar 3 Penanaman bibit buah di Masjid Ciherang Bogor Jawa Barat.

Aktivitas para individu dalam bertanya dan mengemukakan pendapat cukup bervariasi, terutama jika terdapat individu yang mendominasi diskusi kelompok tersebut sehingga dapat mempengaruhi pendapat individu yang lain dalam kelompok. Hollander (2004) menjelaskan bahwa interaksi sosial sekelompok individu tersebut dapat saling mempengaruhi dan menghasilkan data/informasi jika memiliki kesamaan dalam hal, antara lain memiliki kesamaan karakteristik individu secara umum, kesamaan status sosial, kesamaan isu/ permasalahan, dan kesamaan relasi/hubungan secara sosial. Halaman atau pekarangan rumah penduduk merupakan ruang terbuka hijau yang cocok untuk mendukung gerakan penghijauan. Apabila setiap masyarakat memiliki kesadaran untuk menanami halaman rumahnya dengan tanaman, maka penghijauan kota dapat dikatakan berhasil.

Peranan dan fungsi pekarangan sangat penting dalam kehidupan rumah tangga sehari-hari, yaitu sebagai warung hidup yang mana hasil dari bercocok tanam di lahan pekarangan dapat digunakan untuk kegiatan dapur, apotek hidup sebagai tanaman obat keluarga yang sewaktu-waktu dapat digunakan untuk kesehatan, lumbung hidup sebagai cadangan makanan bagi keluarga, dan tabungan hidup sebagai pendapatan keluarga apabila hasil produksi bercocok tanam di lahan pekarangan tersebut dikomersilkan. Mohri et al. (2013) menekankan bahwa pekarangan sangat penting untuk menjaga keseimbangan ekosistem yang dapat memberikan layanan ekosistem kepada penggunanya.

\section{SIMPULAN}

Aksi masyarakat secara signifikan mempengaruhi keberhasilan dan keberlanjutan perwujudan pekarangan produktif di permukiman. pekarangan merupakan ruang terbuka hijau yang memiliki nilai luar biasa dalama menunjang lingkungan.

Kemandirian masyarakat diperlukan pendampingan dan evaluasi program yang dilkasanakan untuk meningkatkan kualitas manusia dalam masyarakat sehingga pemahaman dan ketrampilan meningkat dan menyeluruh di masyarakat.

\section{SARAN}

Penelitian ini memberikan kontribusi dalam menumbuhkan jiwa kesadaran masyarakat pentingnya menjaga kelestarian lingkungan dalam ruang lingkup keluarga dan lingkungan sekitar. Penelitian ini kedepannya diperlukan evaluasi dan monitoring tingkat 
keberhasilan daya tumbuh serta tingkat keberhasilan tumbuh.

\section{UCAPAN TERIMA KASIH}

Terima kasih kepada Forum Wacana Pasca Sarjana IPB - Departemen Pengabdian Masyarakat dan Sekolah Pascasarjana IPB yang telah membatu kegiatan Pengadian Masyarakat. Kementerian Kehutanan dan Lingkungan Hidup yang telah membantu 1000 bibit buah. Serta warga Desa Ciherang Bogor Jawa Barat yang telah menyediakan waktu dan tempat dalam pelakasanaan kegiatan ini.

\section{Daftar Pustaka}

Afiyanti Y. 2008. Focus group discussion (diskusi kelompok terfokus) sebagai metode pengumpulan data penelitian kualitatif. Jurnal Keperawatan Indonesia 12(1): 5862.

[BPS]. Badan Pusat Statistik. Kota Bogor 2013
Hollander JA. 2004. The social contexts of focus groups. Journal of Contemporary Ethnography 33(5): 602-637.

Irwan SN, Rofiqo, Sarwadi A. 2015. Lanskap Pekarangan Produktif di Permukiman Perkotaan Dalam Mewujudkan Lingkungan Binaan Berkelanjutan, Prosiding Seminar Nasional Sains dan Teknologi 2015 Fakultas Teknik Universitas Muhammadiyah Jakarta , 17 November 2015.

Kitzinger J. 1994. The methodology of focus group interviews: the importance of interaction between research participants. Sociology of Health and IIIness 16: 103-121.

Mohri H, Shruti Lahoti, Osamu Saito, Anparasan Mahalingam , Nimal Gunatilleke, Irham, Van Thang Hoang, Gamini Hitinayake, Kazuhiko Takeuchi, Srikantha Herath. 2013. Assessment of ecosystem services in home-garden systems in Indonesia, Sri Lanka, and Vietnam. Ecosystem Services 5: 124 - 136. 